\title{
ERRATUM
}

\section{Erratum to: Impact of typhoon Lekima (2019) on material transport in Laizhou Bay using Lagrangian coherent structures*}

\author{
Qi LOU ${ }^{1}$, Zhengyan $\mathrm{LI}^{1,2}$, Yanwei ZHANG ${ }^{1}$, Yilei FENG ${ }^{1}$, Xueqing ZHANG ${ }^{1,2, * *}$ \\ ${ }^{1}$ College of Oceanic and Atmospheric Sciences, Ocean University of China, Qingdao 266100, China \\ ${ }^{2}$ Key Laboratory of Marine Science and Numerical Modeling, Ministry of Natural Resources (MNR), Qingdao 266061, China \\ (C) Chinese Society for Oceanology and Limnology, Science Press and Springer-Verlag GmbH Germany, part of Springer Nature 2022
}

Erratum to: https://doi.org/10.1007/s00343-021-0384-7

The authors' affiliations of this article contain a few mistakes. The correct ones are given below:

${ }^{1}$ College of Environmental Science and Engineering, Ocean University of China, Qingdao 266100, China

${ }^{2}$ Key Laboratory of Marine Environment and Ecology, Ministry of Education of China, Ocean University of China, Qingdao 266100, China

The online version of the original articles can be found at: https://doi.org/10.1007/s00343-021-0384-7.

\footnotetext{
* Supported by the National Natural Science Foundation of China (No. 41974085) and the National Key R\&D Program of China (No. 2019YFC1408100) ** Corresponding author: zxq@ouc.edu.cn
} 